\title{
Affinity Interactions as a Tool for Protein Immobilization
}

\author{
Eva Benešová and Blanka Králová \\ The Institute of Chemical Technology, Prague \\ Czech Republic
}

\section{Introduction}

Proteins, biopolymers composed of proteinogenic amino acids, are molecules with irreplaceable functions in human organism. They have among others a role as structural components, they are involved in motion processes, they appear as significant parts of immune response and different types of protection events, they play important roles in transport and storage processes and they also occur in signalling processes. One of the most important protein functions is their role as natural biocatalysts - enzymes, because these compounds, increasing the rate of metabolic reactions, are necessary for almost all reactions in human body. The potential of enzyme application in biotechnological processes was discovered many years ago. The rapid development of molecular biology and protein engineering, enabling targeted designing of proteins with suitable features and their production in recombinant form, contributed in decisive way to the final anchoring of proteins in biotechnological practice including such areas as food industry and medicine. Also different methods of protein immobilization represent a way enabling their common and easy application in biotechnology (Demain \& Vaishnav, 2009; García-Junceda et al., 2004; Murray et al., 2002; Vodrážka, 1999). A part of this improvement, focused on utilization of affinity interactions in immobilization processes, will be the major part of this chapter.

First part of this chapter will be aimed to the explanation of the importance of enzyme application in biotechnological processes and the improvement of their usage caused by immobilization. Advantages and limitations of immobilization processes will be described and some examples of their practical application in biotechnology and pharmaceutical industry will be mentioned. This part will also contain a brief summary of common immobilization techniques.

Second part of this chapter will explain the reasons for recombinant proteins preparation and the advantage of proteins modifications by techniques of molecular biology. A simple strategy for recombinant protein preparation in the simplest expression system of $E$. coli will be described for a better comprehensibility. Different methods of exploitation of affinity interactions for the protein immobilization will be referred in the last part of the chapter. The importance of achieved results for the biotechnological practice will be summarized. 


\section{Immobilization: What, why, how?}

At the beginning of the topic describing immobilization techniques and their advantages we should explain the meaning of the word "immobilization" in this text. A molecule or a cell is referred to be immobilized, if its mobility in the reaction space is artificially restricted. Many various immobilization protocols were evolved as we will show in the next chapter part. It is also necessary to stress at this point that although we have decided to focus on enzyme immobilization, also other molecules (antibodies, DNA etc.) and various cells and cellular organelles may be immobilized. In some cases also systems containing more than one immobilized enzyme were prepared. Such systems may gradually catalyse subsequent reactions in biochemical process (Aehle, 2007; Brena \& Batista-Viera, 2006; Costa et al., 2005; García-Junceda et al., 2004; Guisan, 2006; Hernandez \& Fernandez-Lafuente, 2011; Krajewska, 2004; Rao et al., 1998; Tischer \& Wedekind, 1999).

Generally it is possible to say that enzymes are excellent biocatalysts working under mild reaction conditions (temperature, pressure, $\mathrm{pH}$ ) and evincing high substrate and reaction specificity i.e. biotechnologically important characteristics, which result in production of desired end-product without by-products contamination. For these reasons enzymes found their place in a wide variety of biotechnological areas including among others food industry, medicine and pharmaceutical industry, analytical applications, cosmetics or e.g. textile and paper industry and new and new applications are constantly announced (Aehle, 2007; Brena \& Batista-Viera, 2006; Costa et al., 2005; Cowan \& Fernandez-Lafuente, 2011; Guisan, 2006; Krajewska, 2004; Rodrigues et al., 2011; Sheldon, 2007).

As one example for all we can mention $\beta$-D-galactosidase representing an enzyme very popular in food industry applications. Its importance for the milk processing lies in its ability to hydrolyse lactose, as this ability offers the possibility of lactose free milk preparation, an important product for lactose-intolerant people. The ability of some of these enzymes to catalyze transglycosylation reactions is often utilized for health beneficial galactooligosaccharides production. Crystallization prevention, cheeses ripen improving or whey lactose hydrolysis are other examples of possible biotechnological $\beta$-D-galactosidase application. Several methods were successfully used for immobilization of this enzyme, e.g. physical adsorption, gel entrapment or covalent binding. Also techniques utilizing affinity interactions with fusion $\beta$-D-galactosidases were evolved (Aehle, 2007; Cowan \& Fernandez-Lafuente, 2011; Krajewska, 2004; Panesar et al., 2006).

In order to make enzyme application in biotechnological processes more favourable, different methods for the cost decrease are implemented, immobilization techniques being one of them. Moreover, enzyme application suffers from various other limitations resulting e.g. from low stability, sensitivity to process conditions or from tendency to be inhibited by high concentrations of reaction components of some of these biocatalysts. Improvement of these characteristics is still a challenge for modern biotechnological research and some of these problems found their solution in precisely designed immobilization processes (Aehle, 2007; Cao, 2005; Costa et al., 2005; Guisan, 2006; Hernandez \& Fernandez-Lafuente, 2011; Krajewska, 2004).

Enzyme immobilization enables primarily the re-use or continuous use of the biocatalysts and it also substantially simplifies the manipulation with the biocatalyst and the control of the reaction process. Also the separation of the enzyme from the reaction mixture is 
significantly easier and protein contamination of final product is minimized. Moreover, immobilization is next to molecular biology and protein engineering an alternative method for improving natural features of enzymes as e.g. stability, activity, specificity or selectivity. Anyway, various combinations of above mentioned approaches are possible, i.e. immobilization of suitably modified enzymes or, reversely, modification (physical or chemical) of already immobilized enzyme. Also the unwanted enzyme inhibition caused by reaction components, by aggregation, adsorption, by dissociation into subunits or by autolysis or proteolysis can be positively influenced by precise design of immobilization process. In special cases (therapeutic application etc.) also additional advantages as e.g. prolonged blood circulation lifetime or lower immunogenicity may be observed. As a conclusion it is possible to summarize that enzyme immobilization increases the productivity of these biocatalysts and improves their features, which make them more attractive for various applications. However, in some cases immobilization can cause a lowering of enzyme activity or changes of natural enzyme features in undesirable way. These situations must be prevented. Other complications, which have to be solved during immobilization process designing, represent mass transfer limitations (Aehle, 2007; Cao, 2005; Chern \& Chao, 2005; Costa et al., 2005; Cowan \& Fernandez-Lafuente, 2011; GarcíaJunceda et al., 2004; Guisan, 2006; Hernandez \& Fernandez-Lafuente, 2011; Krajewska, 2004; Liu \& Scouten, 1996; Mateo et al., 2007; Panesar et al., 2006; Rodrigues et al., 2011; Sheldon, 2007; Tischer \& Wedekind, 1999; Turková, 1999).

\subsection{Immobilization techniques}

The main goal of this part is to introduce some basic information about immobilization techniques to the reader. In fact there are few basic protocols used during immobilization processes, all of them having many variations. The description of all details about these methods and their modifications go far beyond the extent of our topic and for this reason we recommend to find details in referred publications.

Immobilization methods are classified differently in various publications. We have chosen for immobilization techniques classification system of three major classes 1) binding to a carrier, 2) entrapment and 3) enzyme molecules cross-linking. However, another ways of sorting e.g. according to the reversibility of the process are also frequently used. In fact all classifications suffer from the fact that many newly evolved immobilization procedures exceed the border of simple sorting (Aehle, 2007; Brenda \& Batista-Viera, 2006; Cao, 2005; Costa et al., 2005; Krajewska, 2004; Sheldon, 2007; Tischer \& Wedekind, 1999).

\subsubsection{Binding to a carrier}

These methods take the advantage of the fact that proteins contain amino acids with different features. Functional groups in side chains of these amino acids can be involved in binding to the support by various types of linkages and interactions. Many types of carriers with diverse properties were evolved for immobilization processes; however, the suitability of their application in individual cases needs a careful consideration and very often also laborious method adaptation. Preparing a suitable carrier may be seen as another problem and may incur additional costs for the whole immobilization procedure (Aehle, 2007; Brenda \& Batista-Viera, 2006; Sheldon, 2007). 


\section{a. Covalent binding}

For covalent binding of the protein to the carrier amino acid residues not involved in the reaction mechanism may be used. Generally used functional groups are amino groups of lysines and arginines, sulphydryl groups of cysteins, carboxyl groups of aspartic and glutamic acids and hydroxyl groups of tyrosines, serines and threonines. Strength of the linkage not allowing enzyme release from the support during the reaction process and frequent enzyme stability increase counterbalance limitations caused by the possibility of unwanted changes in active structure of the enzyme and thus possible decrease of enzyme activity caused by strong enzyme - carrier interactions (Aehle, 2007; Brenda \& Batista-Viera, 2006; Costa et al., 2005; Ho et al., 2004; Panesar et al., 2006; Rao et al., 1998; Sheldon, 2007).

b. Physical adsorption

In this method, typical for its simple performance and little effect on biocatalysts conformation, several different types of noncovalent interactions (e.g. hydrogen bonds, hydrophobic interactions and van der Waals forces) are involved in the immobilization process. The weakness of support - enzyme interactions, which can be easily influenced by reaction conditions, causing enzyme desorption represents its major limitation (Aehle, 2007; Brenda \& Batista-Viera, 2006; Costa et al., 2005; Ho et al., 2004; Panesar et al., 2006; Sheldon, 2007).

\section{c. Ionic binding}

Ion-ion interactions, providing a stronger binding of immobilized molecules than physical adsorption, are utilized during immobilization process. This method also doesn't change enzyme conformation in a substantial extent. Disadvantages of this relatively simple process may lie in the usage of highly charged supports, which can interact with charged substrates or products and in laborious finding of suitable conditions providing sufficiently strong interaction and preserving the activity of the enzyme (Aehle, 2007; Brenda \& Batista-Viera, 2006; Costa et al., 2005).

\section{d. Affinity binding}

This method is based on the principle of complementary biomolecules interactions, which represents its biggest advantage i.e. high selectivity (Brenda \& Batista-Viera, 2006; Costa, 2005; García-Junceda et al., 2004). Detailed description of this method will be given in the part 2.2.

Principles of above mentioned methods are for illustration presented in the figure 1.

A)

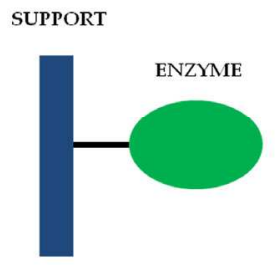

B)

SUPPORT

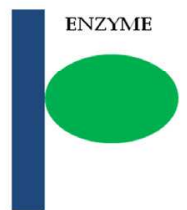

C)

SUPPORT

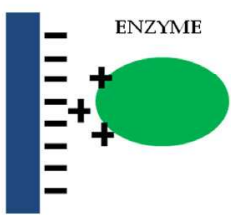

D)

SUPPORT

Fig. 1. Immobilization methods exploiting binding to a carrier. A) covalent binding, B) physical adsorption, C) ionic binding, D) affinity binding 


\subsubsection{Enzyme molecules cross-linking}

In these methods bi- or multifunctional compounds are used for cross-linking of desired enzyme molecules (figure 2). Lysines amino groups are usually involved in covalent bonds formation; however, other amino acids functional groups may be used, too. Since several drawbacks accompany this method, e.g. low activity yields, poor reproducibility or manipulation difficulties, new improvements including cross-linking of enzyme crystals or enzyme aggregates, co-cross-linking with inert materials or cross-linking on solid support or in gels were evolved (Aehle, 2007; Costa et al., 2005; Sheldon, 2007; Tischer \& Wedekind, 1999).

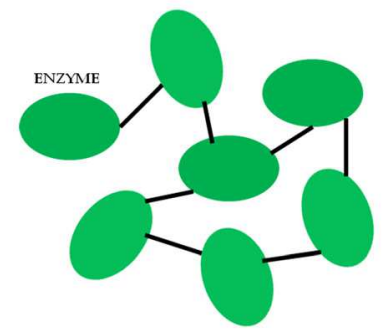

Fig. 2. Cross-linking of enzyme molecules

\subsubsection{Entrapment}

The basis of this method is the inclusion of the biocatalyst within a polymeric network of different types (figure 3). These protocols comprise among others entrapment into gel matrices, microencapsulation or fiber entrapping. Its major advantages consist in simplicity of performance, in the possibility to use similar procedures for different enzymes or even in their simultaneous immobilization and in elimination of inhibition by proteases and inhibitors of high molecular weight. On the other hand, diffusion constraints and the possibility of enzyme leakage belong to the major method limitations (Aehle, 2007; Brenda \& Batista-Viera, 2006; Cao, 2005; Costa et al., 2005; Ho et al., 2004; Panesar et al., 2006; Sheldon, 2007).
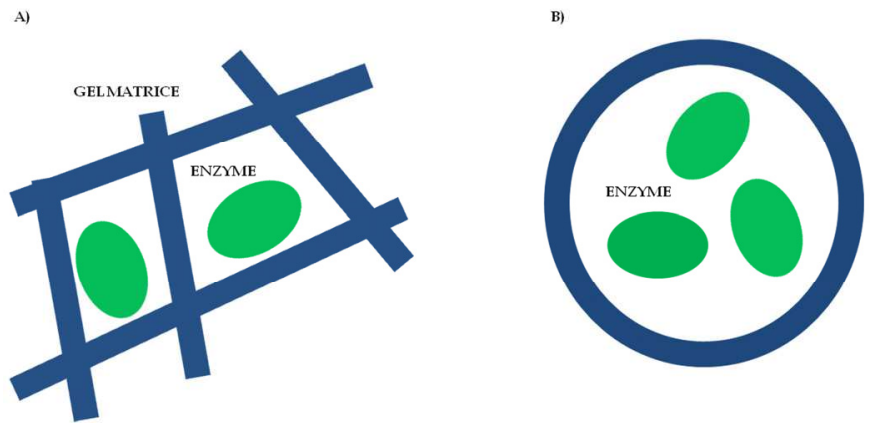

Fig. 3. Enzyme immobilization by entrapment. A) entrapment into gel matrices, B) microencapsulation

Another aspect, which can be used for immobilization methods classification and which should be considered during the choice of immobilization process, is the influence of 
immobilization on enzyme orientation. Standard immobilization protocols without a control of binding mode are usually considered as random immobilization. Such immobilization processes result in heterogeneity in binding nature. This random immobilization may suffer from various drawbacks as e.g. involving of catalytic amino acids residues in the binding process with the subsequent loss of enzymatic activity or restricted accessibility of the active site for substrate molecule. These limitations were overcome in the method of site-specific enzyme immobilization exploiting the attachment of the enzyme due to defined binding sites. As a nice example of different immobilization outcomes a comparative study measured for $\beta$-galactosidase by Vishwanath and co-workers may serve. A conjugate of $\beta$ galactosidase with a polypeptide tail and unmodified $\beta$-galactosidase were immobilized. While a rapid drop of enzymatic activity was observed for the random immobilization of unmodified enzyme (only $1.8 \%$ of original activity detected), tagged $\beta$-galactosidase preserved $87.7 \%$ of original activity, which suggests the attachment due to the polypeptide tail and a positive influence of oriented immobilization. Immobilization techniques utilizing affinity interactions, which will be described in the following part of the chapter, are representatives of oriented immobilization methods (Cao, 2005; Hernandez \& FernandezLafuente, 2011; Kumada et al., 2010; Liu \& Scouten, 1996; Rao et al., 1998; Turková, 1999; Vishwanath et al., 1995).

Although various methods for protein immobilization were evolved, precise designing of immobilization process is still not a routine task. For different enzymes different supporting materials and different immobilization techniques are suitable. Thus in every case of immobilization protocol designing three major things are important to be considered - the enzyme of interest, suitable carrier type and used immobilization method. From the biotechnological point of view also the economical suitability has to be taken into account. Nowadays, the effort to evolve rationally designed and specialized immobilization processes, ideally realized by simple methodologies, is accompanied and facilitated by modern biochemical methods (Aehle, 2007; Brena \& Batista-Viera, 2006; Cao, 2005; Guisan, 2006; Krajewska, 2004; Mateo, 2007; Sheldon, 2007).

\subsection{Methods exploiting affinity interactions for enzymes immobilization}

Following part of the chapter will be focused on the possibility to take an advantage of affinity interactions for protein immobilization. Detailed description will be devoted to the usage of affinity tags and also some other immobilization methods utilizing affinity interactions will be presented at the end of the chapter.

Affinity immobilization techniques exploit the selectivity of specific interactions, which occur in almost all important biological processes in living organisms. Various methods, based on the ability of different affinity partners to bind selectively together (antibodies and antigens or haptens, lectins and free saccharidic chains or glycosylated macromolecules, nucleic acids and nucleic acid-binding proteins, hormones and their receptors, avidin and biotin, polyhistidine tag and metal ions etc.), were discovered for utilization in affinity chromatography or in affinity immobilization methodologies (Carlsson et al., 1998; Nelson \& Cox, 2005; Nilsson et al., 1997; Roy \& Gupta, 2006; Saleemuddin, 1999).

As mentioned earlier the major advantage of utilization of affinity interactions for enzyme immobilization lies in the selectivity of the method. Also the possibility to control the 
orientation of immobilized enzyme and minimal conformational changes caused by this type of binding resulting in high retention of the immobilized molecule activity represent an important benefit. The reversibility of the methods, enabling the support reloading, and the possibility of direct enzyme immobilization from crude cell lysate without additional purification steps contribute to the better applicability of these methods in practice. Mild reaction conditions and relative simplicity of these immobilization processes should also be emphasized (Andreescu et al., 2006; Brena \& Batista-Viera, 2006; Bucur et al., 2004; Clare et al., 2001; Costa et al., 2005; Daunert et al., 2007; Kumada et al., 2010; Saleemuddin, 1999).

\subsubsection{Fusion protein affinity tags utilized for protein immobilization}

One way how to use affinity binding in the immobilization process is the approach exploiting possibilities of molecular biology generating recombinant fusion proteins (chimeric proteins), i.e. proteins of interest containing specific parts suitable for affinity interactions. These parts, called affinity tags, are usually amino acids sequences, ranging in size from a few amino acids to whole proteins. A wide variety of these fusion partners was prepared, some of them with the ability to bind small ligands, others interacting with a suitable protein partner. Not negligible advantage of use of fusion protein approach consists in the possibility to attach one type of fusion partner to different proteins of interest. This fact enables the usage of one support type, preparation of which can sometime be very expensive or complicated, for immobilization of various enzymes (Arnau et al., 2006; Chern \& Chao, 2005; Costa et al., 2005; Daunert et al., 2007; Nilsson et al., 1997; Sørensen \& Mortensen, 2005; Rao et al., 1998; Saleemuddin, 1999; Terpe, 2003).

It is important to mention that immobilization is not the only reason for recombinant fusion proteins production, although in their ability to enable simple purification (affinity chromatography) and immobilization processes lies their most important advantage. In some cases proteins are produced with suitable fusion partners also for increase of solubility (fusion with maltose-binding protein, thioredoxin, glutathione S-transferase etc.) and stability of original enzyme (maltose-binding protein, thioredoxin etc.), for an improvement of the correct folding of the protein (maltose-binding protein, ubiquitin-based tags etc.) or for an increase of the synthesis of proteins, which are translated only poorly under normal conditions (green fluorescent protein) etc. Fusion partners can be used as specific folding and expression reporters, too (green fluorescent protein, rainbow tags) (Arnau et al., 2006; Altenbuchner \& Mattes, 2005; Arechaga et al., 2003; Baneyx, 1999; Jacquet et al., 1999; Nilsson et al., 1997; Rao et al., 1998; Sørensen \& Mortensen, 2005; Waldo et al., 1999).

Description of various ways of immobilizations enabled by affinity interactions mediated by affinity tags and particular examples will be described in the part 2.2.3. For a better comprehensibility of the recombinant proteins preparation next part of the chapter will be devoted to a brief description of one of the simplest ways for recombinant protein production.

\subsubsection{Recombinant proteins preparation}

Increasing usage of enzymes in broad spectra of biotechnological applications led to a demand on cost-effective processes producing sufficient amounts of desired proteins. The isolation from original sources was very often not suitable (low production in original 
organism, high costs of cultivation process, pathogenicity of the original organisms etc.), but new techniques of molecular biology opened the way for the production of recombinant proteins in host organisms, thus solving many of above mentioned complications (Demain \& Vaishnav, 2009; García-Junceda et al., 2004; Sørensen \& Mortensen, 2005).

Many different expression systems were evolved, including Gram-positive and Gram-negative bacteria, yeasts, fungi and plant, insect or mammalian cells. The reason for different expression systems preparation is the fact, that every system has its advantages and drawbacks and no expression system could be suitable for all demanded proteins. Generally it is possible to say that the choice of correct expression system depends on several factors as e.g. cost, size of the protein, demanded posttranslational modifications, final yield etc. (Arnau et al., 2006; Demain \& Vaishnav, 2009; Gellissen et al., 2005; Primrose et al., 2001). As it is beyond the theme of this chapter, it is not possible to explain here all details related to all individual expression systems. For illustration we will briefly describe the usage of one mostly used expression system using the best known and described bacteria (E. coli) and we will also outline one of possible strategies for recombinant proteins production.

E. coli is the microorganism serving for a long decades for scientific purposes. For its convenience it is nowadays one of the most often used organisms for research and also for industrial purposes in the recombinant enzymes production. But even this expression system has its limitations. The inability to produce glycosylated proteins can be named as one example. Therefore, research based on genetic engineering focuses aims to overcome some shortcomings and thus increase the possibility of application of these microorganisms in many new industrial processes (Baneyx, 1999; Demain \& Vaishnav, 2009; Altenbuchner \& Mattes, 2005; Sørensen \& Mortensen, 2005).

Every strategy for preparation of recombinant protein in a host cell consists of four basic steps (Primrose et al., 2001).

1. In the first step it is necessary to have the possibility to prepare DNA fragment containing the gene encoding the desired protein.

2. Prepared DNA is inserted into a chosen vector. Plasmids, nowadays mostly commercially prepared, are often used as suitable DNA vectors.

3. Prepared expression plasmid is introduced into host cells.

4. Host cells after plasmid DNA introduction are cultivated on suitable media and positive colonies containing expression plasmid for recombinant protein production are detected (Altenbuchner \& Mattes, 2005; Primrose et al., 2001; Sørensen \& Mortensen, 2005; Vodrážka, 1999).

A scheme of the process of recombinant protein production is for a better comprehensibility shown in the figure 4.

Another advantage offered by recombinant proteins production is the possibility of modification of the original nucleotide sequence encoding the protein of interest. For example suitable alterations in the original structure of the protein may result in desirable changes of its stability, activity or specificity. However, for the topic of this chapter the fact that on both termini of the gene special DNA sequences may be ligated, which are responsible for a production of original polypeptide chain with additional polypeptide sequences, which can be used as affinity tag for immobilization processes, is important. These positions of fusion tags usually don't represent any obstacle for the catalytic centre 
and thus for a correct enzymatic function of the protein (Andreescu et al., 2006; Arnau et al., 2006; Bucur et al., 2004; Demain \& Vaishnav, 2009; Rao et al., 1998).

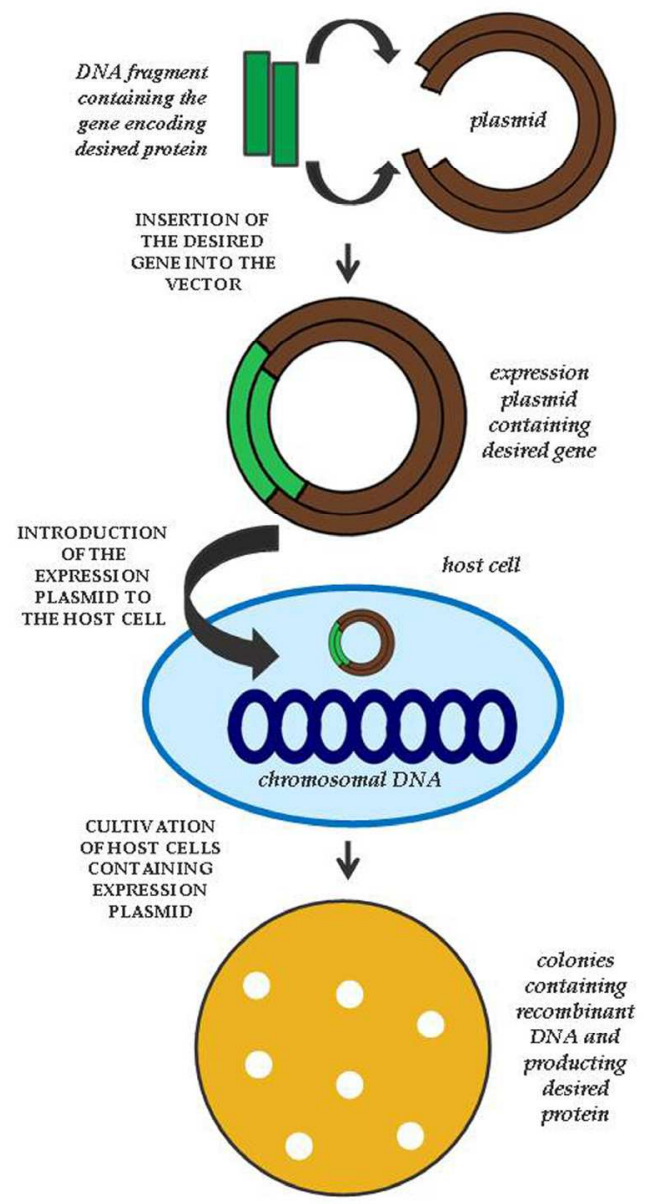

Fig. 4. Recombinant protein preparation

It should be once more emphasized that only one of the simplest strategies for recombinant protein production was described and for more precise description of cloning methods, gene manipulations and expression system advantages the reader is recommended to search in mentioned works.

\subsubsection{Affinity tags used for protein immobilization}

As stated earlier, following paragraphs will discuss the most interesting affinity tags, which were used for enzyme immobilization. In many cases these tags are often used also for affinity chromatography enabling very effective purification of desired proteins. General principle of these methods is illustrated in the figure 5. 


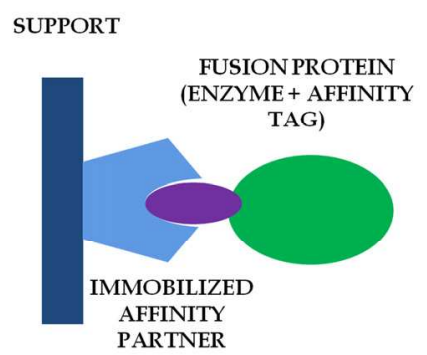

Fig. 5. Principle of immobilization methods enabled by affinity tags

\subsubsection{Immobilization by polyhistidine tags}

This method, based on the specific interaction of histidine-rich tags of different length attached to the protein of interest and of metal ions immobilized on the matrix $\left(\mathrm{Ni}^{2+}, \mathrm{Cu}^{2+}\right.$, $\mathrm{Zn}^{2+}$ etc.), belongs to a group of immobilized metal affinity adsorption techniques. The attachment of polyhistidine tag to different protein partners was used in many cases for purification processes and also the interest of its possible employment in immobilizations is under intensive investigation. The reversibility of the method and thus the reuse of the supports can be ensured by using competitive ligand (e.g. imidazole or histidine) or by usage of metal ions chelator like EDTA. This method, although used in many immobilization experiments, can in some cases suffer from different complications. For example leaching of the metal ions from the support can cause product contamination. Also the interference of large number of metal-binding proteins or additional interactions between the immobilized protein and affinity support may represent a serious limitation. Several authors stated also relatively low binding affinity (similarly as for glutathione Stransferase tag or maltose-binding tag) as an important restriction of use of these affinity tags in immobilization processes. However, polyhistidine-tags exploiting immobilization techniques were successfully used e.g. for acetylcholine esterase, $\beta$-galactosidase, lactate dehydrogenase, $\beta$-glucuronidase or D-hydantoinase immobilization. During the development of methods exploiting the interaction with metal ions various tags of different composition, containing additional amino acid residues, were prepared too (Bucur et al., 2004; Daunert et al., 2007; Desai et al., 2002; Hernandez \& Fernandez-Lafuente, 2011; Ho et al., 2004; Nilsson et al., 1997; Rao et al., 1998; Roy \& Gupta, 2006; Saleemuddin, 1999; Takakura et al., 2010; Terpe, 2003).

\subsubsection{Immobilization using avidin-biotin interaction}

Another strategy for affinity immobilization exploits extraordinarily strong affinity interaction (probably one of the strongest noncovalent interactions between two biomolecules) between vitamin $\mathrm{H}$ - biotin (figure 6) and egg white glycoprotein avidin or its bacterial alternative streptavidin originating from Streptomyces avidinii. Biotinylated proteins may be attached to the support containing avidin as an interaction partner. The preparation of biotinylated conjugates is usually not accompanied by a significant loss of activity; however, chemical approaches result in heterogenous population of desired biotinylated protein. Methods of genetic engineering may represent a solution of above mentioned complication. $\beta$-Galactosidase may be given as an example of an enzyme immobilized by this strategy. In some cases (e.g. keratinkinase, $\beta$-galactosidase, trypsin) reversely fusion 
proteins of desired enzyme and streptavidin can be immobilized on a biotinylated support. During detailed research also other affinity tags with the ability to bind biotin were discovered. As an example tamavidin 2, a fungal avidin-like protein, used as affinity tag e.g. for sialyltransferase from Photobacterium sp. JT-ISH-224 immobilization on biotin carrying support, can be mentioned (Clare et al., 2001; Costa et al., 2005; Hernandez \& FernandezLafuente, 2011; Nilsson et al., 1997; Rao et al., 1998; Takakura et al., 2010; Turková, 1999).

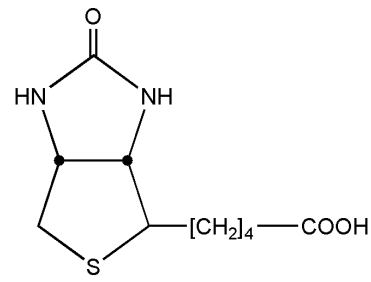

Fig. 6. Biotin

\subsubsection{Immobilization by cellulose-binding domain}

It is known that some bacterial or fungal proteins, e.g. exoglucanase and endoglucanase from Cellulomonas fimi or cellulase from Trichoderma harzianum, are able to specifically bind cellulose thanks to their cellulose-binding domain. These domains may be exploited as affinity tags for fusion proteins immobilization on cellulose supports, which are inert and exhibit only low non-specific affinity and are readily available. A genetically based fusion protein technique of this type was used e.g. for $\beta$-glucosidase from Agrobacterium sp., Zymomonas mobilis extracellular invertase or Bacillus stearothermophilus L1 lipase. Alternative method using chemical coupling by glutaraldehyde was utilized for preparation of a conjugate containing glucose oxidase and cellulose-binding domain. As an interesting intermethodical example the immobilization technique used for alkaline phosphatase and $\beta$ glucosidase can be mentioned. In this case a chimeric protein containing cellulose-binding domain and streptavidin was prepared, attached on cellulose support and used for immobilization of biotinylated forms of above mentioned enzymes (Chern \& Chao, 2005; Clare et al., 2001; Daunert et al., 2007; Hernandez \& Fernandez-Lafuente, 2011; Hwang et al., 2004; Rao et al., 1998; Roy \& Gupta, 2006; Saleemuddin, 1999; Terpe, 2003).

\subsubsection{Immobilization by chitin-binding domain}

Chitin represents another example of suitable affinity support, which is among other nontoxic, biodegradable and commonly occurring in the nature and thus available at relatively low cost. Chitin-binding domain, originating e.g. from chitinase A1 of Bacillus circulans WL-12, serves as appropriate affinity tag in these cases. D-Hydantoinase can be mentioned as an example of an enzyme successfully produced with a chitin-binding domain affinity tag and immobilized on chitin support. It can be supposed that also this type of affinity support will find a broader application field in the future (Chern \& Chao, 2005; Daunert et al., 2007; Krajewska, 2004; Terpe, 2003).

\subsubsection{Immobilization exploiting calmodulin as an affinity tag}

Immobilization techniques utilizing the calcium-binding regulatory protein calmodulin as an affinity tag are based on the highly specific interaction of this molecule (attached to the 
protein of interest) with its phenothiazine ligand (figure 7). Oriented immobilized enzyme can be easily removed from the support thanks to $\mathrm{Ca}^{2+}$ dependence of the interaction process enabling the support regeneration. Covalent binding of the phenothiazine ligand to the support prevents the leaching of the ligand. This immobilization technique was used e.g. for organophosphorus hydrolase or $\beta$-lactamase (Daunert et al., 2007; Desai et al., 2002).

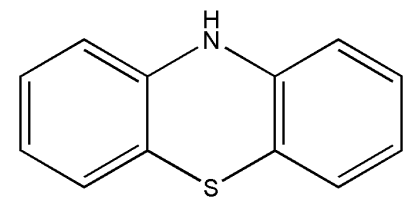

Fig. 7. Phenothiazine

We would like to end this part, devoted to the topic of utilization of affinity tags for protein immobilization, with directing the attention to the fact that also many others affinity tags were tested to be suitable as a tool for enzyme immobilization. However, mentioning all of them exceeds possibilities of this communication. As examples we can mention immobilization by polystyrene-binding peptides with their ability to specifically bind hydrophilic polystyrene supports, immobilization by DNA hybridization, exploiting the ability of polynucleotide chains of DNA to pair according to the rules of complementarity, or by using glutathione S-transferase tag, which is able to specifically bind to glutathione (Daunert et al., 2007; Kumada et al., 2010; Paternolli et al., 2002).

\subsubsection{Other approaches for affinity immobilization}

Although the methods of molecular biology and genetic engineering for fusion protein production are very useful and popular in immobilization strategies, in some cases native features of proteins of interest are possible to be exploit for the immobilization, too. A few examples of this type of techniques are mentioned in the following paragraphs. In some cases a very tight relations between these methods and earlier described principles based on fusion protein preparation are evident.

\subsubsection{Glycoproteins immobilization}

For the immobilization of glycoproteins (proteins posttranslationally modified by carbohydrate attachment to hydroxyl groups of serine and threonine or to amide group of asparagine) their specific interaction with carbohydrate-binding proteins i.e. lectins can be used. This type of posttranslational modification is very common in nature and was observed in many eukaryotes, archaebacteria or even in some prokaryotes. The specificity of above mentioned interactions was many times exploited in affinity based purification procedures. Concanavalin A originating from Jack bean (Canavalia ensiformis), displaying selectivity for defined mannosylated and glucosylated structures, is the mostly used lectin in immobilization processes. Considering the fact that carbohydrate chains are usually not involved in catalytical processes, this method of immobilization as a rule doesn't evince significant influence on the catalytic activity of the enzyme. Promising results obtained for a glycoprotein acetylcholine esterase by Bucur and co-workers were published recently. Also other glycoenzymes, as for example glucose oxidase, invertase, $\beta$-galactosidase, carboxypeptidase $\mathrm{Y}$ or amyloglucosidase, were immobilized by this way. However, high 
cost for lectin supports can represent a limitation of application of these techniques and thus new ways for inexpensive carriers' preparation are searched. Even on this field new methodologies were achieved. As an example the immobilization utilizing an affinity boronate gel also called as "general lectin", which is able to interact with many polar functional groups of suitable structure, can be mentioned. Although having a lower specificity for recognized carbohydrate structure, its advantages lie in its stability and lower cost. This technique was successfully used e.g. for horseradish peroxidase immobilization. Methods exploiting glycosyl specific antibodies supports, which are highly specific for a glycoenzyme of interest, were also reported as an alternative for glycoproteins immobilization (Ahmad et al., 2001; Bucur et al., 2004; Bucur et al., 2005; Liu \& Scouten, 1996; Nelson \& Cox, 2005; Rao et al., 1998; Roy \& Gupta, 2006; Saleemuddin, 1999; Tischer \& Wedekind, 1999; Turková, 1999).

\subsubsection{Immobilization methods based on antibodies-antigens interactions}

Several immobilization methods exploit the interaction specificity of antibodies (monoclonal or polyclonal) and their antigens. It is almost impossible to describe all evolved variations ranging from the simplest immobilization of protein on a support covered with appropriate antibody (used for e.g. carboxypeptidase A, trypsin, chymotrypsin), continuing with exploiting secondary antibodies (e.g. immobilization of horseradish peroxidase via monoclonal enzyme specific antibody and anti-Fc antibodies) to preparation of fusion protein and its interaction with anti-tag antibody (used for alkaline phosphatase). An important role in these techniques is played also by two antibodies-binding proteins, i.e. Protein A from Staphylococcus aureus with the ability to specifically bind the Fc region of immunoglobulins and streptococcal Protein G with broader binding abilities. Both mentioned proteins enable oriented immobilization of antibodies on the surface, thus ensuring a correct orientation of antibody binding sites for further interaction. Next to favourable possibility to control the orientation of immobilized enzyme also other advantages are connected with antibody-antigen interaction using immobilization techniques, e.g. the fact that antibodies represent a spacer separating the enzyme and the matrix ensuring thus enough space required for correct enzymatic activity. Some limitations may be represented by relatively high costs of monoclonal antibody preparation. As mentioned at the beginning of the paragraph, many different variations and improvements, encompassing e.g. using two simultaneously attached affinity tags, preparation of Fcbinding unit of Protein A or coimmobilization of two enzymes, were evolved. Also methods, where e.g. IgG or Protein A were used as affinity tags, were reported (Daunert et al., 2007; Nilsson et al., 1997; Rao et al., 1998; Roy \& Gupta, 2006; Saleemuddin, 1999; Solomon et al., 1991; Turková 1999).

For methods based on the interaction of histidine-rich enzyme parts and metal chelate supports an alternative that doesn't exploit strategies of genetic engineering exists, too. Some proteins, as for example alkaline phosphatase, lysozyme or ribonuclease A, are able to bind these supports also in their native form. Chemical procedure increasing the amount of surface histidine of glycoproteins was tested for Penicillium chrysogenum glucose oxidase and horseradish peroxidase. Similar interactions, observed between phosphorylated proteins and immobilized metal ions $\left(\mathrm{Ga}^{3+}, \mathrm{Fe}^{3+}\right.$ etc.), may be utilized e.g. for enrichment of phosphoproteins in studied samples or for phosphorylated proteins and peptides purification. For phosphoproteins immobilization their ability to bind alumina can be 
exploit as confirmed e.g. for pepsine, which contains a phosphoserine residue. Also for this type of interaction an alternative method converting enzymes of interest to phosphoproteins was evolved and successfully used for e.g. subtilisin (Chaga, 2001; Hernandez \& FernandezLafuente, 2011; Machida et al., 2007; Rao et al., 1998; Saleemuddin, 1999; Schmidt et al., 2007).

At the end of this chapter it is again necessary to emphasize that different variations and combinations of all above mentioned methods are possible and new improvements are published every year. As one nicely illustrative example a combined method used for alkaline phosphatase immobilization may serve. In this technique a fusion protein strategy and antibody-antigen interaction were connected, because a tagged protein was immobilized by specially prepared anti-tag antibodies (Hernandez \& Fernandez-Lafuente, 2011).

\section{Conclusion}

The idea of enzyme immobilization has introduced a totally new look on using these excellent biocatalysts in technological processes. Immobilized enzymes have a big potential for biotechnological practice for their important economical, technological and ecological advantages. Some weak points in immobilization techniques, as e.g. possible lowering of enzyme activity, was a challenge for the modern research and has led to development of a broad range of immobilization methods.

Utilization of affinity interactions for protein immobilization is a new trend, which is nowadays intensively examined. Many interesting variations of these strategies are based on natural specific interactions of molecules; many others are exploiting new findings of molecular biology and genetic engineering. Though affinity immobilization techniques are nowadays studied by many research teams, there are still new possibilities in finding simple, effective and inexpensive methods that would enable the use of immobilized enzymes in common technological practice. Many successful results from recent years indicate the importance of affinity immobilization techniques in these innovative methodologies.

\section{Acknowledgment}

Publishing of this work was supported by the Ministry of Education, Youth and Sports (MSM6046137305).

\section{References}

Aehle, W. (2007). Enzymes in industry (third edition), Wiley-VCH, ISBN 978-3-527-31689-2, Weinheim

Ahmad, S.; Anwar, A. \& Saleemuddin, M. (2001). Immobilization and stabilization of invertase on Cajanus cajan lectin support. Bioresource Technology, Vol.79, No.2, pp. 121-127, ISSN 0960-8524

Altenbuchner, J. \& Mattes, R. (2005). Escherichia coli, In: Production of recombinant proteins: novel microbial and eukaryotic expression systems, G. Gellissen, (Ed.), 7-43, Wiley-VCH, ISBN 3-527-31036-3, Weinheim 
Andreescu, S.; Bucur, B. \& Marty, J.-L. (2006). Affinity immobilization of tagged enzymes, In: Immobilization of enzymes and cells. (second edition), J. M. Guisan, (Ed.), Humana Press Inc., ISBN 1-59745-053-7, New Jersey

Arechaga, I.; Miroux, B.; Runswick, M. J. \& Walker, J. E. (2003). Over-expression of Escherichia coli $\mathrm{F}_{1} \mathrm{~F}_{0}$-ATPase subunit a is inhibited by instability of the uncB gene transcript. FEBS Letters, Vol.547, No.1-3, pp. 97-100, ISSN 0014-5793

Arnau, J.; Lauritzen, C.; Petersen, G. E. \& Pedersen, J. (2006). Current strategies for the use of affinity tags and tag removal for the purification of recombinant proteins. Protein Expression and Purification, Vol.48, No.1, pp. 1-13, ISSN 1046-5928

Baneyx, F. (1999). Recombinant protein expression in Escherichia coli. Current Opinion in Biotechnology, Vol.10, No.5, pp. 411-421, ISSN 0958-1669

Brena, B. M. \& Batista-Viera, F. (2006). Immobilization of enzymes, In: Immobilization of enzymes and cells. (second edition), J. M. Guisan, (Ed.), Humana Press Inc., ISBN 159745-053-7, New Jersey

Bucur, B.; Danet, A. F. \& Marty, J.-L. (2004). Versatile method of cholinesterase immobilisation via affinity bonds using Concanavalin A applied to the construction of a screen-printed biosensor. Biosensors and Bioelectronics, Vol.20, No.2, pp. 217-225, ISSN 0956-5663

Bucur, B.; Danet, A. F. \& Marty, J.-L. (2005). Cholinesterase immobilisation on the surface of screen-printed electrodes based on concanavalin A affinity. Analytica Chimica Acta, Vol.530, No.1, pp. 1-6, ISSN 0003-2670

Carlsson, J.; Janson, J.-C. \& Sparrman, M. (1998). Affinity chromatography, In: Protein purification. Principles, high resolution methods, and applications. (second edition). J.-C. Janson \& L. Rydén, (Ed.), Viley-VCH, ISBN 0-471-18626-0, New York

Cao, L. (2005). Carrier-bound immobilized enzymes. Principles, Application and Design (first edition), Wiley-VCH, ISBN 978-1-61583-208-8, Weinheim

Chaga, G. S. (2001). Twenty-five years of immobilized metal ion affinity chromatography: past, present and future. Journal of Biochemical and Biophysical Methods, Vol.49, No.13, pp. 313-334, ISSN 0165-022x

Chern, J.-T. \& Chao, Y.-P. (2005). Chitin-binding domain based immobilization of Dhydantoinase. Journal of Biotechnology, Vol.117, No.3, pp. 267-275, ISSN 0168-1656

Clare, D. A.; Valentine, V. W.; Catignani, G. L. \& Swaisgood, H. E. (2001). Molecular design, expression, and affinity immobilization of a trypsin-streptavidin fusion protein. Enzyme and Microbial Technology, Vol. 28, No. 6, pp. 483-491, ISSN 0141-0229

Costa, S. A.; Azevedo, H. S. \& Reis, R. L. (2005). Enzyme immobilization in biodegradable polymers for biomedical applications, In: Biodegradable systems in tissue engineering and regenerative medicine. R. L. Reis \& J. S. Román, (Ed.), CRC Press LLC, ISBN 9780-203-49123-2, London

Cowan, D. A. \& Fernandez-Lafuente, R. (2011). Enhancing the functional properties of thermophilic enzymes by chemical modification and immobilization. Enzyme and Microbial Technology, Vol.49, No.4, pp. 326-346, ISSN 0141-0229

Daunert, S.; Bachas, L. G.; Schauer-Vukasinovic, V.; Gregory, K.J.; Schrift, G. \& Deo, S. (2007). Calmodulin-mediated reversible immobilization of enzymes. Colloids and Surfaces B: Biointerfaces, Vol.58, No.1, pp. 20-27, ISSN 0927-7765

Demain, A. L. \& Vaishnav, P. (2009). Production of recombinant proteins by microbes and higher organism. Biotechnology Advances, Vol.27, No. 3, pp. 297-306, ISSN 0734-9750 
Desai, U, A.; Sur, G.; Daunert, S.; Babbitt, R. \& Li, Q. (2002). Expression and affinity purification of recombinant proteins from plants. Protein Expression and Purification, Vol.25, No.1, pp. 195-202, ISSN 1046-5928

García-Junceda, E.; García-García, J. F.; Bastida, A. \& Fernández-Mayoralas, A. (2004). Enzymes in the synthesis of bioactive compounds: the prodigious decades. Bioorganic \& Medicinal Chemistry, Vol.12, No.8, pp. 1817-1834, ISSN 0968-0896

Gellissen, G.; Strasser, A. W. M. \& Suckow, M. (2005). Key and criteria to the selection of an expression platform, In: Production of recombinant proteins: novel microbial and eukaryotic expression systems, G. Gellissen, (Ed.), 1-5, Wiley-VCH, ISBN 3-527-310363, Weinheim

Guisan, J. M. (2006). Immobilization of enzymes as the 21st century begins, In: Immobilization of enzymes and cells. (second edition), J. M. Guisan, (Ed.), Humana Press Inc., ISBN 1-59745-053-7, New Jersey

Hernandez, K. \& Fernandez-Lafuente, R. (2011). Control of protein immobilization: Coupling immobilization and side-directed mutagenesis to improve biocatalyst or biosensor performance. Enzyme and Microbial Technology, Vol.48, No.2, pp. 107-122, ISSN 0141-0229

Ho, L.-F.; Li, S.-Y.; Lin, S.-C. \& Hsu, W.-H. (2004). Integrated enzyme purification and immobilization processes with immobilized metal affinity adsorbents. Process Biochemistry, Vol.39, No.11, pp. 1573-1581, ISSN 1359-5113

Hwang, S.; Ahn, J.; Lee, S.; Lee, T. G.; Haam, S.; Lee, K.; Ahn, I.-S. \& Jung, J.-K. (2004). Evaluation of cellulose-binding domain fused to a lipase for the lipase immobilization. Biotechnology Letters, Vol.26, No.7, pp. 603-605, ISSN 1573-6776

Jacquet, A.; Daminet, V.; Haumont, M.; Garcia, L.; Chaudoir, S.; Bollen, A. \& Biemans, R. (1999). Expression of a recombinant Toxoplasma gondii ROP2 fragment as a fusion protein in bacteria circumvents insolubiliy and proteolytic degradation. Protein Expression and Purification. Vol.17, No.3, pp. 392-400, ISSN 1046-5928

Krajewska B. (2004). Application of chitin- and chitosan-based materials for enzyme immobilization: a review. Enzyme and Microbial Technology, Vol.35, No.2-3, pp. 126139, ISSN 0141-0229

Kumada, Y.; Kuroki, D.; Yasui, H.; Ohse, T. \& Kishimoto, M. (2010). Characterization of polystryrene-binding peptides (PS-tags) for site-specific immobilization of proteins. Journal of Bioscience and Bioengineering, Vol.109, No.6, pp. 583-587, ISSN 1389-1723

Liu, X.-C. \& Scouten, W. H. (1996). Studies on oriented and reversible immobilization of glycoprotein using novel boronate affinity gel. Journal of Molecular Recognition, Vol.9, No.5-6, pp. 462-467, ISSN 1099-1352

Machida, M.; Kosako, H.; Shirakabe, K.; Kobayashi, M.; Ushiyama, M.; Inagawa, J.; Hirano, J.; Nakano, T.; Bando, Y.; Nishida, E. \& Hattori, S. (2007). Purification of phosphoproteins by immobilized metal affinity chromatography and its application to phosphoproteome analysis. FEBS Journal, Vol.274, No.6, pp. 15761587, ISSN 1742-4658

Mateo, C.; Palomo, J. M.; Fernandez-Lorente, G.; Guisan, J. M. \& Fernandez-Lafuente, R. (2007). Improvement of enzyme activity, stability and selectivity via immobilization techniques. Enzyme and Microbial Technology, Vol.40, No.6, pp. 1451-1463, ISSN 0141-0229 
Murray, R. K.; Granner, D. K.; Mayes, P. A. \& Rodwell, V. W. (2002). Harperova biochemie (twenty-third edition), H+H, ISBN 80-7319-013-3, Jinočany

Nelson, D. L. \& Cox, M. M. (2005). Principles of Biochemistry (fourth edition), W. H. Freeman \& Co., ISBN 0-7167-4339-6, New York

Nilsson, J.; Ståhl, S.; Lundeberg, J.; Uhlén, M \& Nygren, P. (1997). Affinity fusion strategies for detection, purification and immobilization of recombinant proteins. Protein Expression and Purification, Vol.11, No.1, pp. 1-16, ISSN 1096-0279

Panesar, P. S.; Panesar, R.; Singh, R. S.; Kennedy, J. F. \& Kumar, H. (2006). Microbial production, immobilization and applications of $\beta$-D-galactosidase. Journal of Chemical Technology and Biotechnology, Vol.81, No.4, pp. 530-543, ISSN 1097-4660

Paternolli, C.; Ghisellini, P. \& Nicolini, C. (2002). Development of immobilization techniques of cytochrome P450-GST fusion protein. Colloids and Surfaces B: Biointerfaces, Vol.23, No.4, pp. 305-311, ISSN 0927-7765

Primrose, S. B.; Twyman, R. M. \& Old, R. W. (2001). Principles of Gene Manipulation (sixth edition), Blackwell Science Ltd, ISBN 0-632-05954-0, Oxford

Rao, S. V.; Anderson, K. W. \& Bachas, L. G. (1998). Oriented immobilization of proteins. Microchimica Acta, Vol.128, No.3-4, pp. 127-143, ISSN 1436-5073

Rodrigues, R. C.; Berenguer-Murcia, Á \& Fernandez-Lafuente, R. (2011). Coupling chemical modification and immobilization to improve the catalytic performance of enzymes. Advanced Synthesis \& Catalysis, Vol.353, No.13, pp.2216-2238, ISSN 1615-4150

Roy, I. \& Gupta, M. N. (2006). Bioaffinity immobilization, In: Immobilization of enzymes and cells. (second edition), J. M. Guisan, (Ed.), Humana Press Inc., ISBN 1-59745-053-7, New Jersey

Saleemuddin, M. (1999). Bioaffinity based immobilization of enzymes. Advances in biochemical engineering/biotechnology, Vol.64, pp. 203-226, ISSN 1616-8542

Schmidt, S. R.; Schweikart, F. \& Andersson, M. E. (2007). Current methods for phosphoprotein isolation and enrichment. Journal of Chromatography, Vol.849, No.12, pp.154-162, ISSN 1570-0232

Sheldon, R. A. (2007). Enzyme immobilization: The quest for optimum performance. Advanced Synthesis \& Catalysis. Vol.349, No.8-9, pp. 1289-1307, ISSN 1615-4169

Solomon, B.; Hadas, E.; Koppel, R.; Schwartz, F. \& Fleminger, G. (1991). Highly active enzyme preparations immobilized via matrix conjugates anti-Fc antibodies. Journal of Chromatography, Vol.539, No.2, pp. 335-341, ISSN 0021-9673

Sørensen, H. P. \& Mortensen, K. K. (2005). Advanced genetic strategies for recombinant protein expression in Escherichia coli. Journal of Biotechnology, Vol.115, No.2, pp. 113128, ISSN 0168-1656

Takakura, Y.; Oka, N.; Kajiwara, H.; Tsunashima, M.; Usami, S.; Tsukamoto, H.; Ishida, Y. \& Yamamoto, T. (2010). Tamavidin, a versatile affinity tag for protein purification and immobilization. Journal of Biotechnology, Vol.145, No.4, pp. 317-322, ISSN 0168-1656

Terpe, K. (2003). Overview of tag protein fusions: from molecular and biochemical fundamentals to commercial systems. Applied Microbiology and Biotechnology, Vol.60, No. 5, pp. 523-533, ISSN 1432-0614

Tischer, W. \& Wedekind, F. (1999). Immobilized enzymes: Methods and applications, In: Biocatalysis - From discovery to application. Topics in Current Chemistry, Vol.200, pp. 95-126. W.-D. Fessner, (Ed.), Springer, ISSN 0340-1022, Berlin 
Turková, J. (1999). Oriented immobilization of biologically active proteins as a tool for revealing protein interactions and function. Journal of Chromatography B, Vol.722, No.1-2, pp. 11-31, ISSN 1570-0232

Vishwanath, S.; Bhattacharyya, D.; Huang, W. \& Bachas, L. G. (1995). Site-directed and random enzyme immobilization on functionalized membranes: kinetic studies and models. Journal of Membrane Science, Vol.108, No. 1-2, pp. 1-13, ISSN 0376-7388

Vodrážka, Z. (1999). Biochemie (second edition), Academia, ISBN 80-200-0600-1, Praha

Waldo, G. S.; Standish, B. M.; Berendzen, J. \& Terwilliger, T. C. (1999). Rapid protein-folding assay using green fluorescent protein. Nature Biotechnology, Vol.17, No.7, pp. 691695, ISSN 1087-0156 


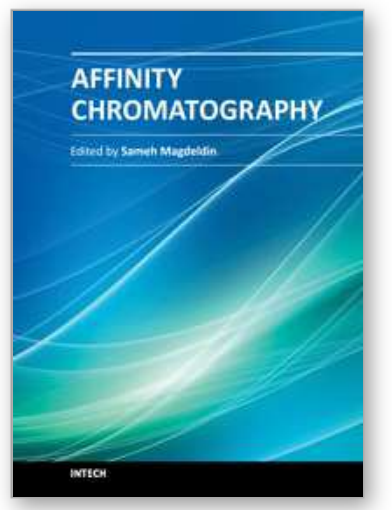

\author{
Affinity Chromatography \\ Edited by Dr. Sameh Magdeldin
}

ISBN 978-953-51-0325-7

Hard cover, 368 pages

Publisher InTech

Published online 21, March, 2012

Published in print edition March, 2012

Most will agree that one major achievement in the bio-separation techniques is affinity chromatography. This coined terminology covers a myriad of separation approaches that relies mainly on reversible adsorption of biomolecules through biospecific interactions on the ligand. Within this book, the authors tried to deliver for you simplified fundamentals of affinity chromatography together with exemplarily applications of this versatile technique. We have always been endeavor to keep the contents of the book crisp and easily comprehensive, hoping that this book will receive an overwhelming interest, deliver benefits and valuable information to the readers.

\title{
How to reference
}

In order to correctly reference this scholarly work, feel free to copy and paste the following:

Eva Benešová and Blanka Králová (2012). Affinity Interactions as a Tool for Protein Immobilization, Affinity Chromatography, Dr. Sameh Magdeldin (Ed.), ISBN: 978-953-51-0325-7, InTech, Available from: http://www.intechopen.com/books/affinity-chromatography/affinity-interactions-as-a-tool-for-a-proteinimmobilization

\section{INTECH}

open science | open minds

\section{InTech Europe}

University Campus STeP Ri Slavka Krautzeka 83/A 51000 Rijeka, Croatia

Phone: +385 (51) 770447

Fax: +385 (51) 686166 www.intechopen.com

\section{InTech China}

Unit 405, Office Block, Hotel Equatorial Shanghai No.65, Yan An Road (West), Shanghai, 200040, China 中国上海市延安西路65号上海国际贵都大饭店办公楼405单元 Phone: +86-21-62489820

Fax: +86-21-62489821 
(C) 2012 The Author(s). Licensee IntechOpen. This is an open access article distributed under the terms of the Creative Commons Attribution 3.0 License, which permits unrestricted use, distribution, and reproduction in any medium, provided the original work is properly cited. 